\title{
Establishment of renal failure models by laparoscopy in bama pigs which underwent partial nephrectomy and radical contralateral nephrectomy
}

\author{
Hai-Feng Liu ${ }^{1,2}$, Hui Li $^{2}$, Ge Bai ${ }^{2}$, Qian-Zhen Zhang ${ }^{2}$, \\ Xiang-Gao ${ }^{2}$, Tao Liu ${ }^{2}$, Hong-Bin Wang ${ }^{2}$ \\ ${ }^{1}$ Department of Veterinary Surgery, College of Veterinary Medicine, \\ Sichuan Agricultural University, Chengdu 611130, P.R. China \\ ${ }^{2}$ Department of Veterinary Surgery, College of Veterinary Medicine, \\ Northeast Agricultural University, Harbin 150030, P.R. China \\ hbwang1940@163.com
}

Received: December 24, 2018 Accepted: August 6, 2019

\begin{abstract}
Introduction: The miniature pig possesses unmatched advantages as an animal model because of its high homology with humans. Our experiment aimed to build a chronic renal failure (CRF) model in pigs via laparoscopy. Material and Methods: Laparoscopic surgery was performed twice to build a CRF model. The first surgery was a left partial nephrectomy and the second was a right radical nephrectomy. Pigs were grouped by the total renal tissue to be resected: $2 / 3,3 / 4$ or $5 / \%$. Physiological parameters (rectal temperature and heart rate), haematological parameters (WBC and $\mathrm{RBC}$ ) and renal function (serum creatinine $-\mathrm{CR}$ and blood urea nitrogen - BUN) were measured preoperatively and every week postoperatively. Results: After renal resection the pigs manifested chronic renal failure. Heart rate and body temperature declined to varying degrees over 12 postoperative weeks. No significant difference was observed between the different groups. The result of renal function tests found that postoperative serum $\mathrm{CR}$ and BUN in all groups were continuously elevated, and the level of serum CR at two weeks post procedure differed very significantly from its preoperative value $(\mathrm{P}<0.05)$. BUN was significantly elevated at one week $(\mathrm{P}<0.05)$. The renal function decreased significantly faster in the $5 / 6$ group than in the other two groups. The trend of renal function change was similar among groups, but progress was slower in the $2 / 3$ and $3 / 4$ groups. Conclusion: $5 / 6$ kidney resection was the optimal miniature pig model of CRF.
\end{abstract}

Keywords: miniature pig, chronic renal failure, animal model, laparoscopy, nephrectomy.

\section{Introduction}

The study of establishment of a chronic renal failure (CRF) model has been made in many animals including guinea pigs, rabbits, cats, sheep, dogs, rats, and mice $(6,20)$. A CRF model can be established through physical, chemical or biological methods, but animals with renal tissue resection have been held up as a successful CRF model (8). Alevy et al. (1) performed renal artery ligation and removal of the contralateral kidney attempting to establish a rat CRF model. However, it was difficult to operate on the animal and easy to cause its death. The application of liquid nitrogen and electrocoagulation and the removal of the contralateral kidney did not give a good result either (2).

The miniature pig has unmatched advantages as an animal model because of its high homology with humans. In recent years, the miniature pig has received more and more attention as a comparative medicine animal model $(5,17)$ and has been widely used in many fields of medicine $(11,12,16)$. Laparoscopic studies for many surgical procedures have been performed on small animals $(14,15)$. Renal failure investigations have been undertaken exploiting small animals as the model; however, no report of a miniature pig renal failure model established through laparoscopy has been published. 


\section{Material and Methods}

Animals. A total of 15 healthy female Bama miniature pigs aged 8-10 months with an average body weight of $22.04 \pm 3.3 \mathrm{~kg}$ were used. The pigs were obtained from the Bama miniature pig farm of the College of Life Sciences (Harbin, China). The pigs were housed under constant temperature and lighting conditions (a $12 \mathrm{~h}$ light/dark cycle as the latter). The animals were housed individually and fed a piglet diet (Shenzhen Jinxinnong Feed, China) and given tap water ad libitum. All pigs were preoperatively assessed as healthy after a physical examination and complete blood count.

Surgical procedure. The pigs were divided into three equal groups: a $2 / 3$ group, a $3 / 4$ group, and a $5 / 6$ group. Animals in the $2 / 3$ group were subjected to a $1 / 3$ left nephrectomy and a right radical nephrectomy, animals in the $3 / 4$ group had a $1 / 2$ left nephrectomy and a right radical nephrectomy performed, and animals in the $5 / 6$ group underwent a $2 / 3$ left nephrectomy and a right radical nephrectomy. All animals were fasted for $24 \mathrm{~h}$ before surgery. Each pig was premedicated with subcutaneous injection of atropine sulphate $(0.04 \mathrm{mg} / \mathrm{kg})$ and intramuscular cefazolin $(20 \mathrm{mg} / \mathrm{kg})$, and subsequently general anaesthesia was induced with intramuscular xylazine $(1 \mathrm{mg} / \mathrm{kg})$ and ketamine hydrochloride $(10 \mathrm{mg} / \mathrm{kg})$ and maintained with $1.5-3 \%$ isoflurane in oxygen after intubation.

The CRF model was established by two laparoscopic surgeries. The left partial nephrectomy was performed in the first surgery and the right radical nephrectomy was performed $10 \mathrm{~d}$ later. All the surgical procedures were performed under sterile conditions.

Pigs were positioned in the right lateral decubitus in the first surgery and left lateral decubitus in the second surgery. Pneumoperitoneum was created with a Veress needle and maintained at $12 \mathrm{mmHg}$. Three ports were opened. Port 1 was created with a trocar and cannula unit (diameter 10-11 mm, Olympus Corporation, Japan) for laparoscope access (Olympus Corporation). Ports 2 and 3 were the access for the laparoscopic instruments. All the surgical procedures were performed in the laparoscopic view.

The renal artery and the renal vein were separated and then clipped temporarily with haemostatic clips (5.7 cm, Shanghai Medical Instrument Co., China); $2 / 3$ of the kidney was removed along the midpoint between the lateral margin and the renal hilum in the $5 / 6$ group, and a part of the kidney was removed from one side in the $2 / 3$ and $3 / 4$ groups. The collecting system of the kidney was sutured; 2-0 absorbable suture was used to close the renal cross-section in a continuous pattern (Fig. 1). In case the suture did not maintain adequate tension, medium titanium clips were used to clamp the site. The medullary substance was embedded close to the cortex.

Then the suture was confirmed. The clamp on the renal artery was removed to ensure haemostasis had been achieved and assess the security of the sutures through the renal parenchyma. The two haemostatic clips were released completely when there was no haemorrhage, and extra suturing was required and carried out if haemorrhage occurred. Physiological saline was infused into the abdominal cavity for lavage and drawn out by a vacuum extractor. A thick aseptic plastic bag was used to pull the renal tissue out through the expanded incision. All laparoscopic instruments were removed and the pneumoperitoneal gas was expelled manually. The incisions were then sutured. The right unilateral nephrectomy was performed seven days after the first surgery. The kidney was radically removed after the renal artery, vein and ureter were ligatured and divided.

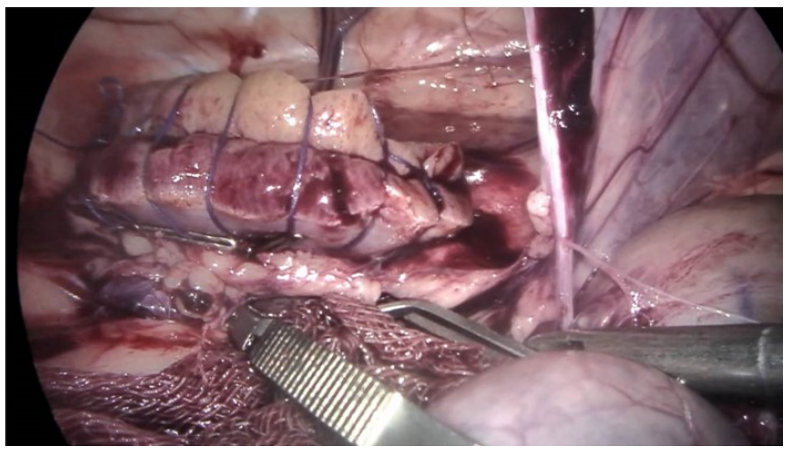

Fig. 1. The clamped artery was released two seconds after suturing to confirm haemostasis. The two haemostatic clips were released completely when there was no haemorrhage

Monitoring and postoperative care. All animals were kept and monitored in the same environment. Their mental state, movement, incision condition, appetite, and excreta were closely monitored every day for 15 days. The pigs were placed in a warm room after anaesthesia and transferred to a sty $6 \mathrm{~h}$ later. Freely available water was provided $6 \mathrm{~h}$ postoperatively, and pig feed was provided $18 \mathrm{~h}$ postoperatively.

A 5-mg fentanyl patch (Duragesic; Janssen Pharmaceutica, Belgium) was applied after surgery, and renewed every three days for six days. Antibiotic prophylaxis consisted of intramuscular cefazolin sodium $(50 \mathrm{mg} / \mathrm{kg}$, Harbin Pharmaceutical Group Co. General Factory, China) administered twice a day for two days.

Baseline values for all measured data were defined before anaesthesia. All pigs were monitored for three days preoperatively and each week after surgery for 12 weeks. Serum creatinine (CR), blood urine nitrogen (BUN), heart rate (HR), rectal temperature, operating time, warm ischaemia time, and total incision length were recorded. Blood samples were collected through the cranial vena cava. The haematological examination included white blood cell (WBC) and red blood cell (RBC) counts and was performed immediately after sample collection with an MEK-7222K haematology analyser (Nihon Kohden Corporation, Japan). Serum was stored at $-80^{\circ} \mathrm{C}$ after centrifugation. 
A total of $300 \mathrm{mg}$ of xylocaine was injected intravenously for euthanasia after general anaesthesia with xylazine and ketamine hydrochloride at 13 weeks, or earlier if a serious complication occurred.

Histopathological examination. Tissue was collected from the caudal pole of the remnant kidney. The renal tissue was fixed in $10 \%$ buffered formalin, embedded in paraffin, and sliced in $3 \mu \mathrm{m}$-thick sections. Sections were stained with haematoxylineosin to evaluate histopathological injury. Five pictures of each sample were analysed to compare changes over the weeks after surgery.

Statistical analysis. Data are presented as the mean \pm standard deviation. One-way ANOVA (and parametric) analysis and analysis of normal distribution by the Kolmogorov-Smirnov method were used to compare the results at different time points in each group. Two-way repeated measures ANOVA analysis was used to compare the results among groups. Oneway ANOVA was performed when incision length and intraoperative blood loss were analysed. $\mathrm{P}$ values $<0.05$ were considered to be statistically significant.

\section{Results}

All the CRF models were established successfully through the pair of surgical procedures. One of three extents of partial nephrectomy and a contralateral radical nephrectomy was successfully performed on each of the 15 animals. None of the animals in any of the groups had intra- or perioperative complications, and no animal's laparoscopic surgery was converted to an open procedure.

Body weight was similar among the three groups (the $2 / 3$ group weighed $23.1 \pm 2.25 \mathrm{~kg}$, the $3 / 4$ group $22.02 \pm 1.48 \mathrm{~kg}$, and the $5 / 6$ group $21.58 \pm 2.84 \mathrm{~kg}$ ). The incisions for both surgeries were the shortest in the $2 / 3$ group and the longest in the $5 / 6$ group $(p>0.05$; those of the $2 / 3$ group measured $8.12 \pm 0.33 \mathrm{~cm}$, those of the $3 / 4$ group $9.22 \pm 0.69 \mathrm{~cm}$, and those of the $5 / 6$ group $9.47 \pm 0.83 \mathrm{~cm})$. Appetite recovered at one day after surgery. All the animals survived for 12 weeks, when they were euthanised. At necropsy, the remnant kidney tissue was hyperplastic and completely buried. Intraoperative blood loss was $5.62 \pm 2.26 \mathrm{ml}$ in the $2 / 3$ group, $4.77 \pm 1.92 \mathrm{ml}$ in the $3 / 4$ group, and $7.91 \pm 3.7 \mathrm{ml}$ in the $5 / 6$ group $(\mathrm{P}>0.05)$.

Physiological parameters. Rectal temperature was measured before surgery to establish a baseline and at designated intra- and postoperative time points. A decreasing trend in rectal temperature was observed after the surgical procedure in all three groups, but there was a significant increase at three days after surgery in all groups compared with the preoperative baseline $(\mathrm{P}<0.05)$. There was no significant change in rectal temperature in any group between any postoperative time points (Fig. 2).

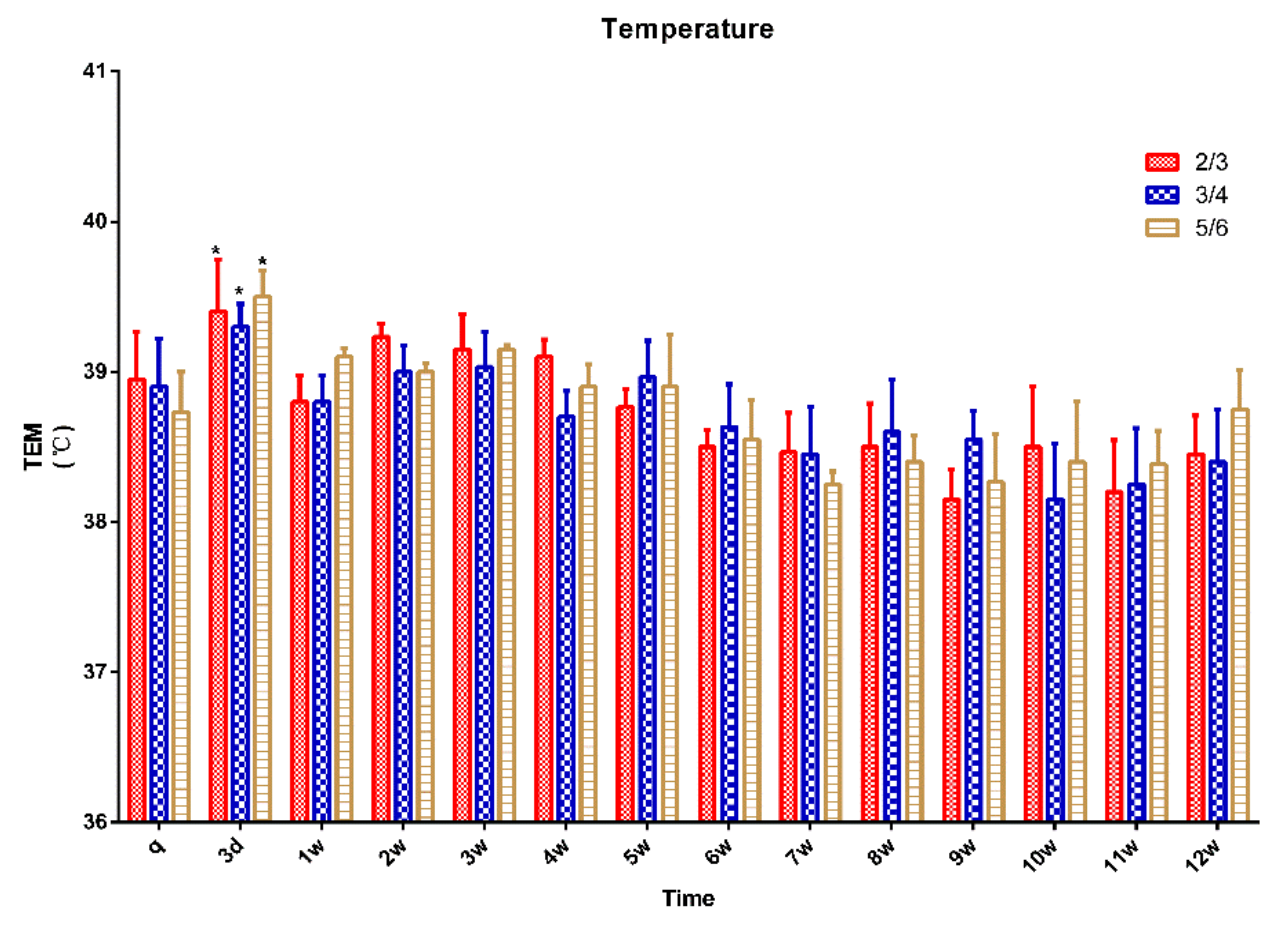

Fig. 2. Rectal temperature in 15 pigs ( $n=5$ for $2 / 3$ group, $n=5$ for $3 / 4$ group, $n=5$ for $5 / 6$ group) $\mathrm{q}$ - preoperative baseline

${ }^{*} \mathrm{p}<0.05$ compared with the preoperative baseline. ${ }^{\mathrm{A}} \mathrm{p}<0.05$ compared with value of $2 / 3$ group at the same time point. ${ }^{\mathrm{B}} \mathrm{p}<0.05$ compared with value of $3 / 4$ group at the same time point 
Heart rate was measured before surgery (baseline) and at the designated intra- and postoperative time points. A decreasing trend in heart rate was observed after the surgical procedure in all three groups, and there was no significant change in heart rate in any group between any postoperative time points (Fig. 3).

Haematological examination. A trend of an initial increase and then a decrease in WBC was observed in all animals and it was significantly higher at three days post procedure than it was preoperatively $(p<0.05)$. It was back to the preoperative level at two weeks in the $2 / 3$ group and at three weeks in the $3 / 4$ and $5 / 6$ groups. There was no significant change in $\mathrm{WBC}$ in any group between any postoperative time points (Fig. 4).

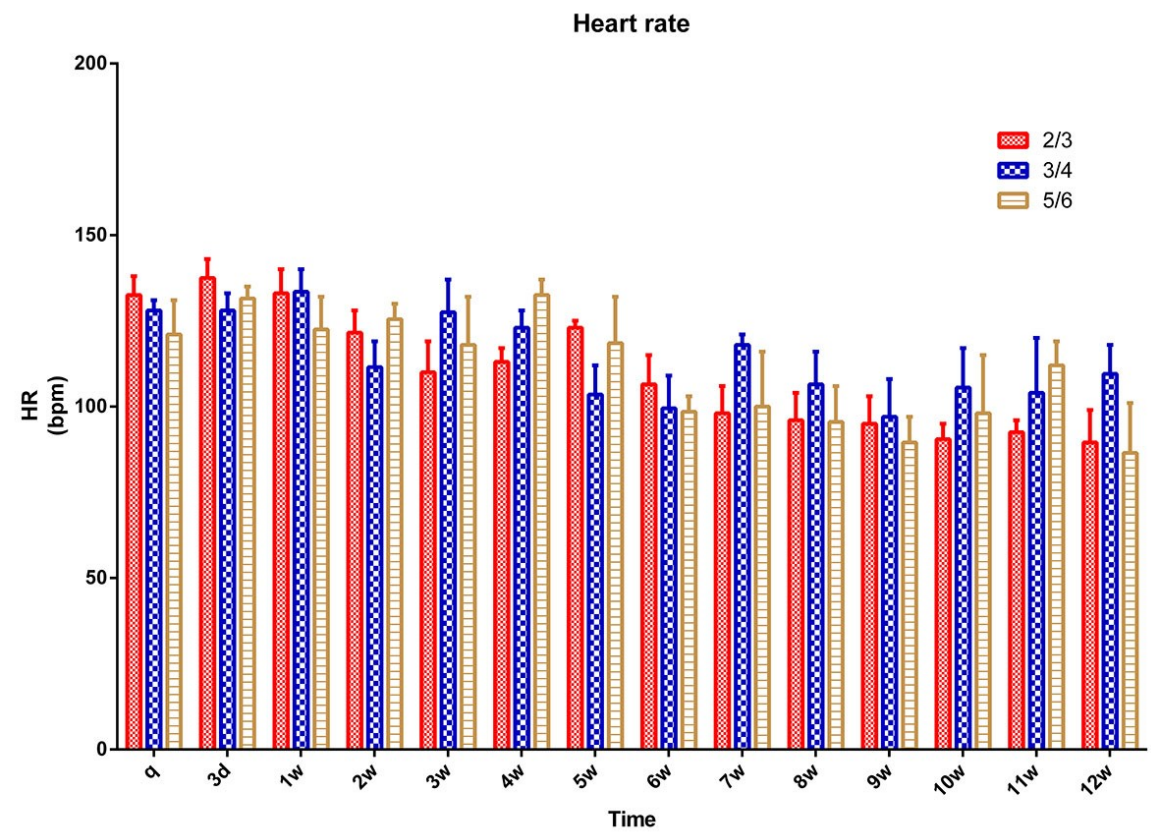

Fig. 3. Heart rate in 15 pigs $(n=5$ for $2 / 3$ group, $n=5$ for $3 / 4$ group, $n=5$ for $5 / 6$ group) $\mathrm{q}$ - preoperative baseline

${ }^{*} \mathrm{p}<0.05$ compared with the preoperative baseline. ${ }^{\mathrm{A}} \mathrm{p}<0.05$ compared with value of $2 / 3$ group at the same time point. ${ }^{\mathrm{B}} \mathrm{p}<0.05$ compared with value of $3 / 4$ group at the same time point

WBC

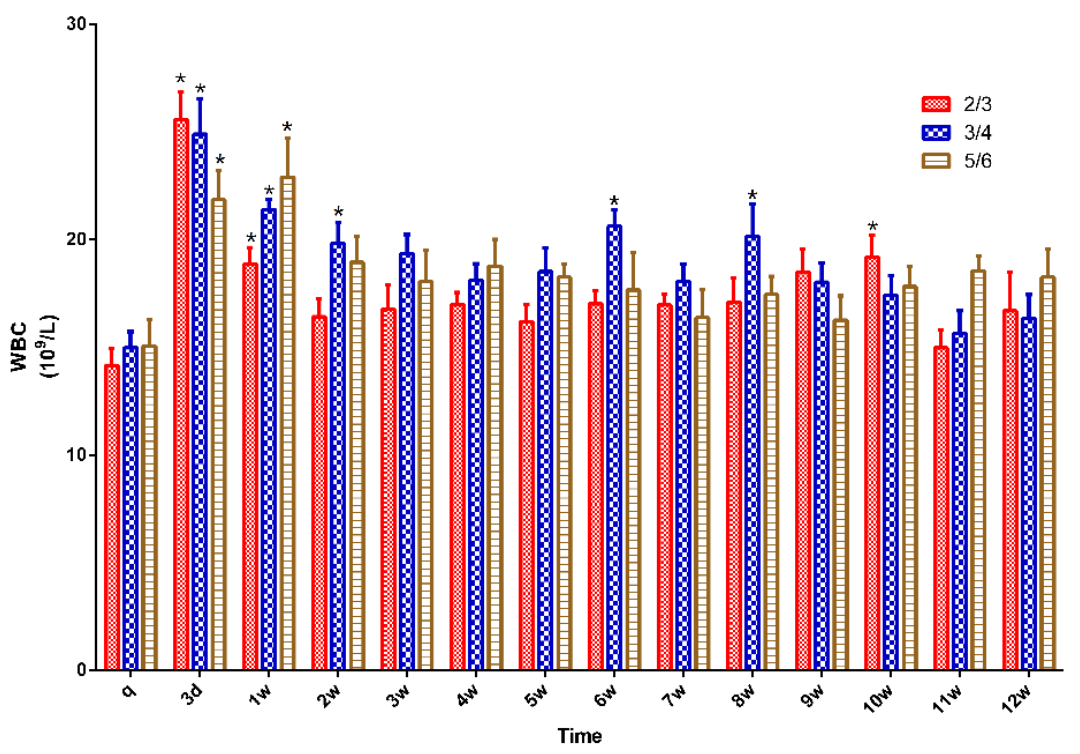

Fig. 4. $W B C$ in 15 pigs ( $n=5$ for $2 / 3$ group, $n=5$ for $3 / 4$ group, $n=5$ for $5 / 6$ group) $\mathrm{q}-$ preoperative baseline

$* \mathrm{p}<0.05$ compared with the preoperative baseline. ${ }^{\mathrm{A}} \mathrm{p}<0.05$ compared with value of $2 / 3$ group at the same time point. ${ }^{\mathrm{B}} \mathrm{p}<0.05$ compared with value of $3 / 4$ group at the same time point 
RBC was decreased in all groups after surgery with no significant change from the preoperative value at any time point. There was no significant change in $\mathrm{RBC}$ in any group between any time points (Fig. 5).

The platelet count (PLT) increased in all groups after surgery on the $3^{\text {rd }}$ day after surgery and then decreased after 1 week with no significant change from the preoperative value at any time point. There was no significant change in PLT in any group between any time points (Fig. 6).

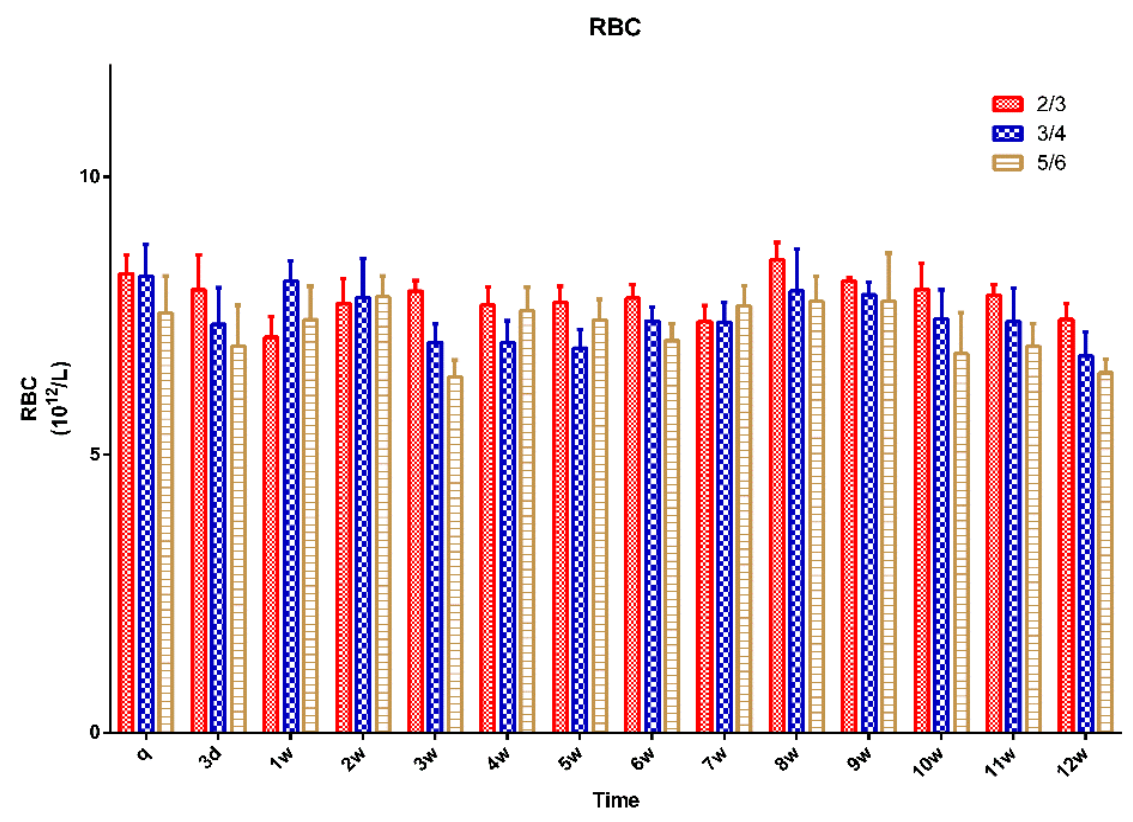

Fig. 5. $\mathrm{RBC}$ in 15 pigs ( $\mathrm{n}=5$ for $2 / 3$ group, $\mathrm{n}=5$ for $3 / 4$ group, $\mathrm{n}=5$ for $5 / 6$ ) group $\mathrm{q}$ - preoperative baseline

${ }^{*} \mathrm{p}<0.05$ compared with the preoperative baseline. ${ }^{\mathrm{A}} \mathrm{p}<0.05$ compared with value of $2 / 3$ group at the same time point. ${ }^{\mathrm{B}} \mathrm{p}<0.05$ compared with value of $3 / 4$ group at the same time point ???

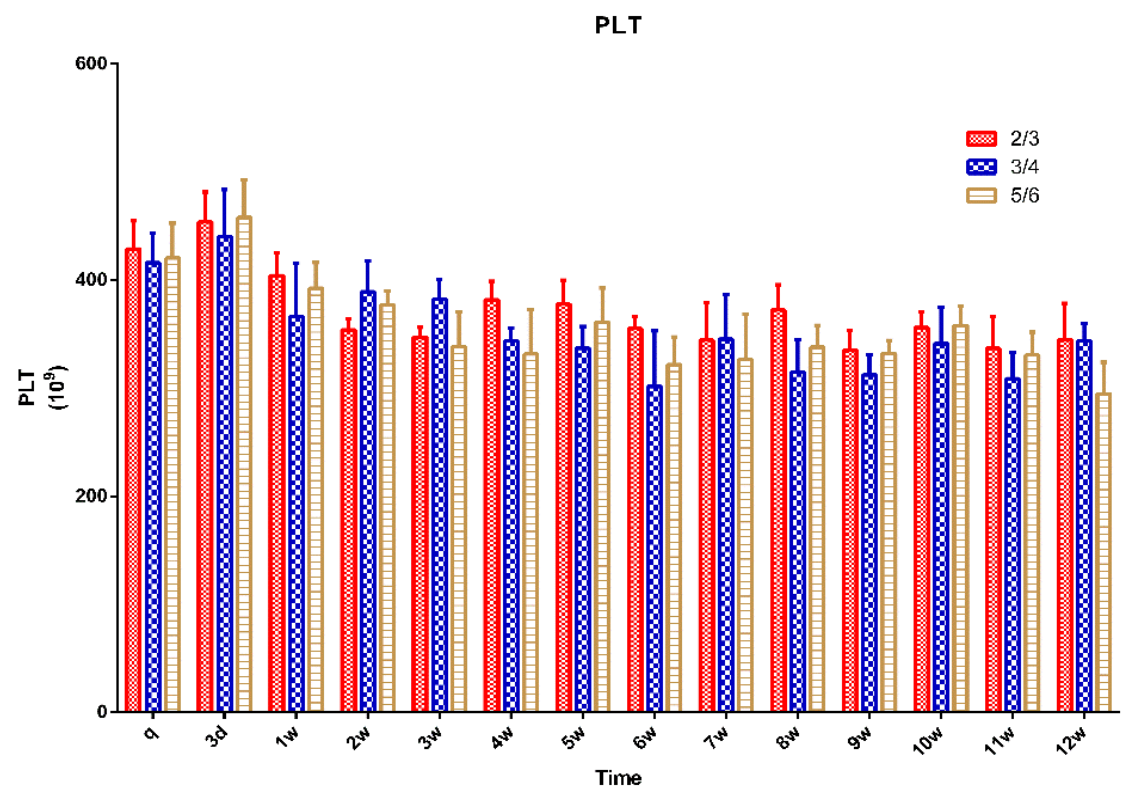

Fig. 6. PLT in 15 pigs ( $n=5$ for $2 / 3$ group, $n=5$ for $3 / 4$ group, $n=5$ for $5 / 6$ group) $\mathrm{q}$ - preoperative baseline

${ }^{*} \mathrm{p}<0.05$ compared with the preoperative baseline. ${ }^{\mathrm{A}} \mathrm{p}<0.05$ compared with value of $2 / 3$ group at the same time point. ${ }^{\mathrm{B}} \mathrm{p}<0.05$ compared with value of $3 / 4$ group at the same time point 
Renal function. The CRE results showed that the concentration of serum CRE continued to increase after surgery in all groups, and it was significantly higher after one postoperative week than preoperatively $(p<0.05)$. It was significantly higher in the $3 / 4$ group at weeks 3,9 , and 10 than in the $2 / 3$ group, and in the $5 / 6$ group after three weeks than in the $2 / 3$ group $(\mathrm{p}<0.05)$ and after six weeks than in the $3 / 4$ group $(\mathrm{p}<0.05)$ (Fig. 7).
The BUN results showed that the concentration of serum BUN increased after surgery in all groups, and it was significantly higher after one postoperative week than it was preoperatively $(\mathrm{p}<0.05)$. It was significantly higher in the $3 / 4$ group at weeks $7,9,10,11$ and 12 than in the $2 / 3$ group. It was also significantly higher in the $5 / 6$ group after seven weeks than in the $2 / 3$ group and after eight weeks than in the $3 / 4$ group (p $<0.05)$ (Fig. 8).

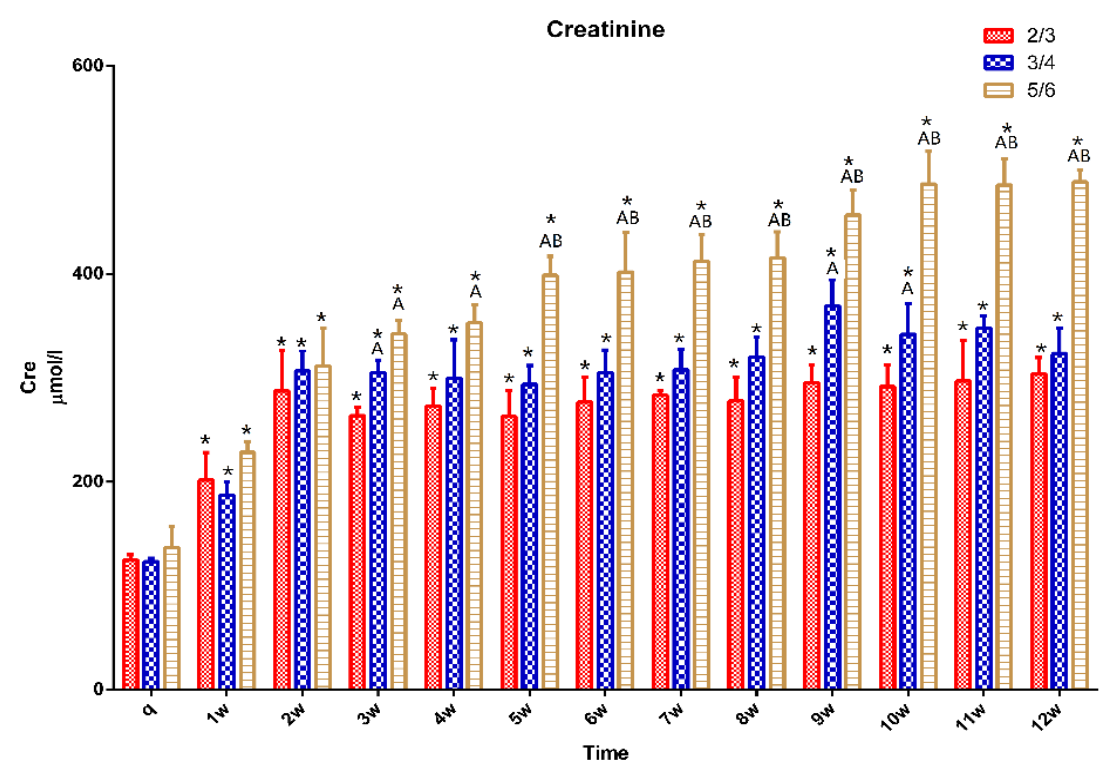

Fig. 7. CRE in 15 pigs ( $n=5$ for $2 / 3$ group, $n=5$ for $3 / 4$ group, $n=5$ for $5 / 6$ group) $\mathrm{q}$ - preoperative baseline

${ }^{*} \mathrm{p}<0.05$ compared with the preoperative baseline. ${ }^{\mathrm{A}} \mathrm{p}<0.05$ compared with value of $2 / 3$ group at the same time point. ${ }^{\mathrm{B}} \mathrm{p}<0.05$ compared with value of $3 / 4$ group at the same time point

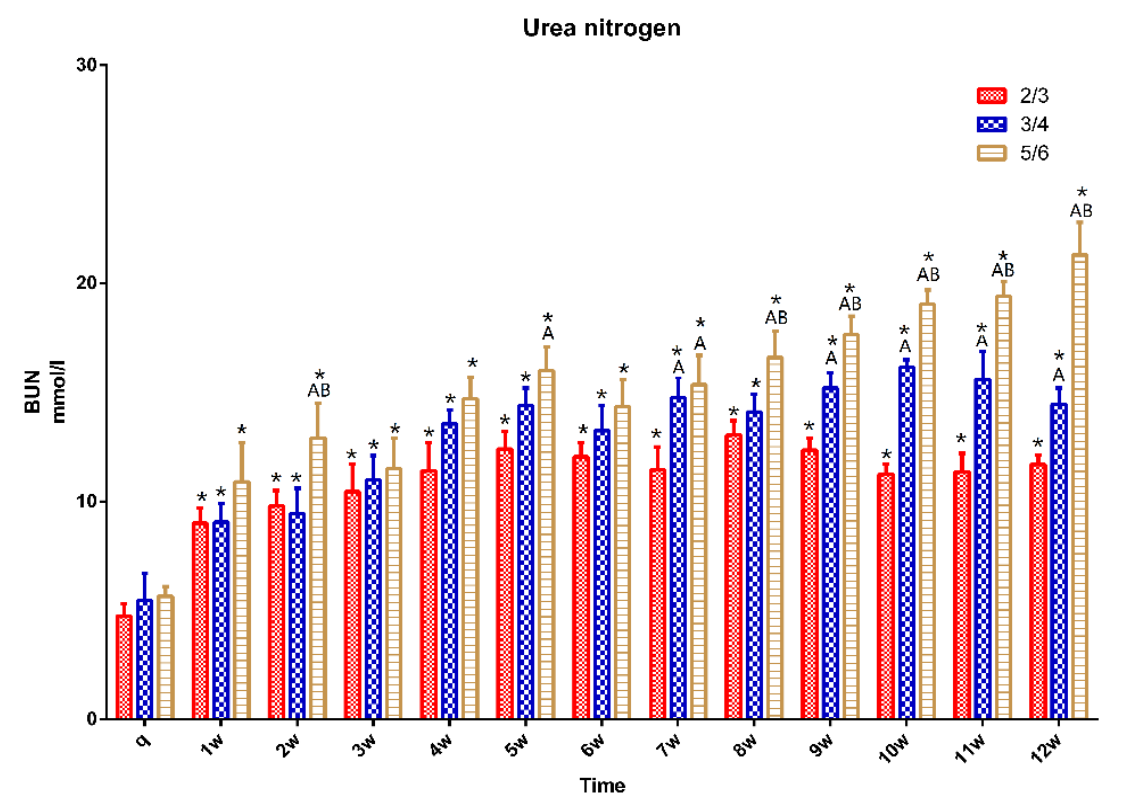

Fig. 8. BUN in 15 pigs $(n=5$ for $2 / 3$ group, $n=5$ for $3 / 4$ group, $n=5$ for $5 / 6$ group) $\mathrm{q}$ - preoperative baseline

$* \mathrm{p}<0.05$ compared with the preoperative baseline. ${ }^{\mathrm{A}} \mathrm{p}<0.05$ compared with value of $2 / 3$ group at the same time point. ${ }^{\mathrm{B}} \mathrm{p}<0.05$ compared with value of $3 / 4$ group at the same time point 

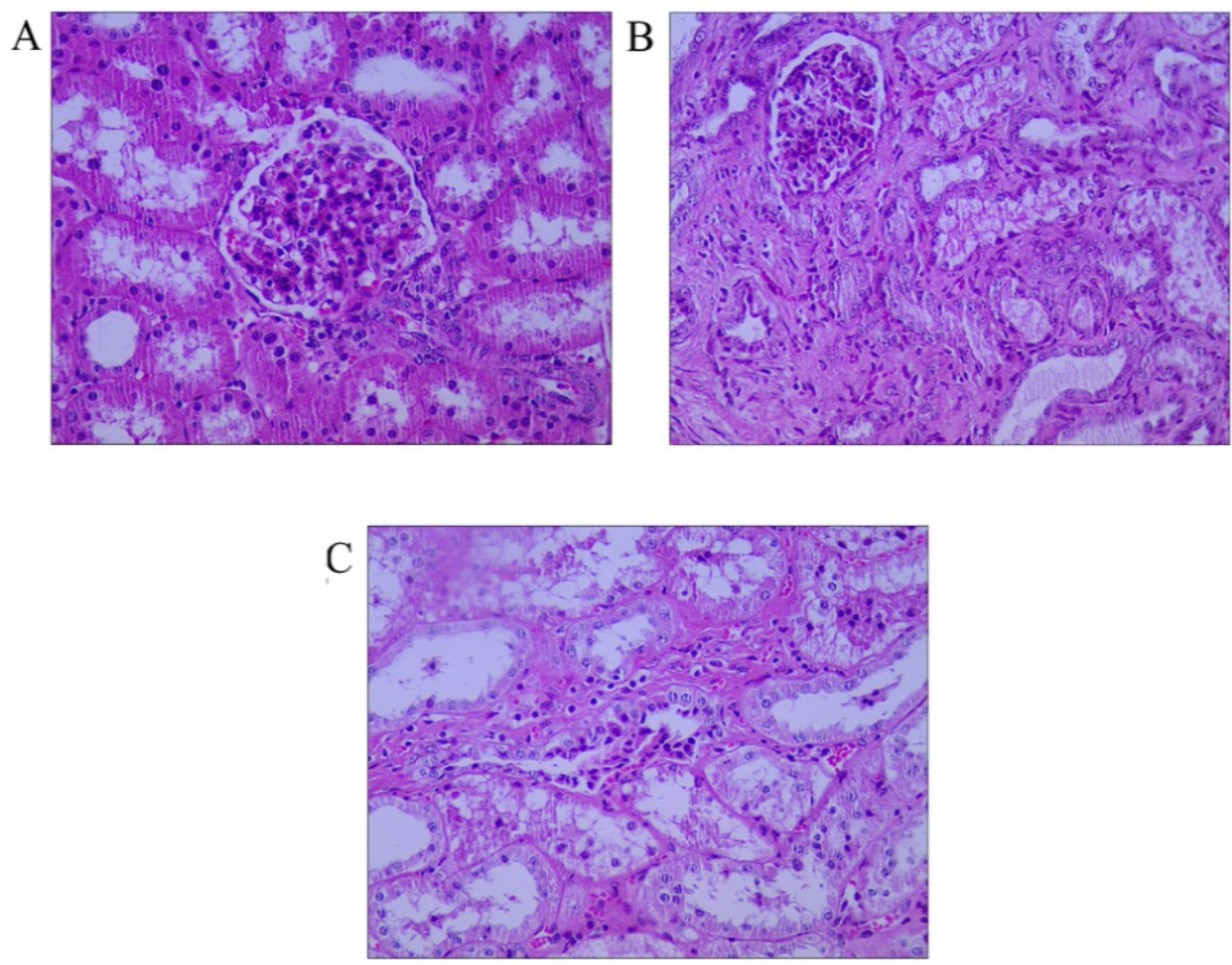

Fig. 9. Histological examination after $5 / 6$ nephrectomy. The picture was captured in microscope vision. A - normal renal tissue, B - at 4 weeks after surgery, C - at 10 weeks after surgery. All at $400 \times$

Histopathological examination. Pathological changes in the kidneys (Fig. 9) showed that pigs had experienced renal tubular damage, tubular dilatation, and occurrence of primitive epithelial cells by 4 weeks and visible renal tubular regeneration, fibrosis, and appearance of new epithelial cells by 10 weeks after surgery.

\section{Discussion}

A significant difference in the change process of renal function was observed between the three groups. Renal function was dramatically decreased in all the animals; however, it deteriorated more slowly in the $2 / 3$ and $3 / 4$ groups. Due to the formidable compensatory ability of the kidney, animals in the $2 / 3$ and $3 / 4$ groups did not reach a compensation failure state rapidly. However, the $5 / 6$ nephrectomy established a CRF model in small animals successfully $(8,22)$, and we found that renal function deteriorated sufficiently steadily that instituting a CRF model in animals with a $5 / 6$ nephrectomy is feasible.

Rat $3 / 4,4 / 5,5 / 6$, and $7 / 8$ nephrectomies have been successful in achieving CRF for study $(4,7,13)$. Our team attempted to build a pig model of CRF because of the homology with humans. We also performed $7 / 8$ nephrectomy in pigs, but we found it difficult to perform the first surgery and the pigs who underwent surgery twice died rapidly. The experiment failed to build a CRF model via $7 / 8$ nephrectomy in pigs.

Partial nephrectomy caused effective nephron decrease and led to potentiation of the compensatory capacity of the remnant renal tissue. The animals showed a diminished renal filtration rate, high protein urine, glomerular sclerosis, and renal interstitial fibrosis. The ultimate result was the pathological characteristics of CRF. Glomerular sclerosis was the major pathological change in the remnant renal tissue and was the direct factor in clinical CRF. Recent studies showed that liquid nitrogen, diathermy, and electrocoagulation along with the removal of the contralateral kidney $(9,10)$ also cause effective nephron reduction; however, the uncertainty about renal damage extent and remnant tissue condition as well as the unpredictability of animal survival detracted from the models' success.

Renal damage after ischaemia has been studied for years. The recommended allowable duration of ischaemia has decreased from $55-40 \mathrm{~min}$ to $30-20 \mathrm{~min}$, with less than $30 \mathrm{~min}$ being identified as the safe duration. However, specialists have proved that once ischaemia starts, renal damage has already occurred, and every minute of ischaemia increases the damage (3). Takagi et al. (19) suggested that renal function was most influenced by the amount of preserved parenchyma and their baseline level of functionality. There have also been reports that the renal glomerular 
filtration rate was associated most strongly with preservation of parenchymal volume, and that ischaemic damage was a causative factor for a fall in this rate only in the short-term phase after surgery. Recently, although researchers have devised and applied techniques for partial nephrectomy without clamping vessels in order to avoid causing ischaemic damage (21), excessive blood loss and haemocyte assimilation by the peritoneum were inevitable. Therefore, in our study the renal vessels were clamped during kidney surgery and suturing, and blood loss resulted mainly from the peritoneal, muscle, and skin incisions. A WBC increase could be observed in most CRF patients because immunity weakened in most of them and the patients were susceptible to other diseases. We did not observe a significant increase in WBC count after surgery, which was possibly because no secondary disease afflicted the subjects.

Different degrees of reduction were observed in the RBC count, which conformed to a pattern similar to that of clinical anaemia. Renal anaemia and haemorrhagic diathesis were the main manifestations of abnormality. Subcutaneous bleeding, mucosal bleeding, bruising, gastrointestinal bleeding, and cerebral haemorrhage can occur in advanced CRF patients (18), and CRF will be more serious if the patients suffer from iron deficiency or malnutrition.

In general, the degree of anaemia was proportional to the renal function of patients; the main reason for anaemia was erythropoietin (EPO) reduction. The decrease in platelet count and the accelerated cell sedimentation rate may be the potential reason for anaemia in CRF patients.

In conclusion, we successfully established miniature pig renal failure models through laparoscopic technique which attests to extensive kidney excision as a feasible means of instituting such a model. The models had high repeatability and weakened postoperative renal function. Pigs in the $2 / 3$ and $3 / 4$ groups experienced slow renal deterioration, and their kidneys were still compensatory. Nephrectomy to $5 / 6$ of total renal tissue is a suitable miniature pig model of CRF.

Conflict of Interest Statement: The authors declare that there is no conflict of interests regarding the publication of this article.

Financial Disclosure Statement: This study was supported by the National Natural Science Foundation of China (grant nos 31272617 and 31472245).

Animal Rights Statement: The present study was approved by the Northeast Agricultural University Institutional Animal Care and Use Committee (approval no. SYXK 2011-0039).

\section{References}

1. Alevy Y.G., Slavin R.G., Hutcheson P.: Immune response in experimentally induced uremia. I. Suppression of mitogen responses by adherent cells in chronic uremia. Immunopathology 1981, 19, 8-18.

2. Boudet J., Man N.K., Pils P., Sausse A., Funck-Brentano J.L.: Experimental chronic renal failure in the rat by electrocoagulation of the renal cortex. Kidney Int 1978, 14, 82-86.

3. Boylu U., Oommen M., Thomas R., Lee B.R.: Transumbilical single-port laparoscopic partial nephrectomy in a pig model. Bju Int 2010, 105, 686-690.

4. Carrillo-López N., Panizo S., Alonso-Montes C., Román-García P., Rodríguez I., Martínez-Salgado C., Dusso A.S., Naves M., Cannata-Andía J.B.: Direct inhibition of osteoblastic Wnt pathway by fibroblast growth factor 23 contributes to bone loss in chronic kidney disease. Kidney Int 2016, 90, 77-89.

5. Cui D., Li F., Li Q., Li J., Zhao Y.F., Hu X.X., Zhang R., Li N.: Generation of a miniature pig disease model for human Laron syndrome. Sci Reports 2015, 5, 15603.

6. Fernandes-Charpiot I.M., Caldas H.C., Mendes G.E., Gomes de Sá Neto L., Oliveira H.L., Baptista M.A., Abbud-Filho M.: Validation of an experimental model to study less severe chronic renal failure. J Invest Surg 2016, 29, 1-7.

7. Ferrari G.O., Ferreira J.C., Cavallari R.T., Neves K.R., dos Reis L.M., Dominguez W.V., Oliveira E.C., Graciolli F.G., Passlick-Deetjen J., Jorgetti V., Moysés R.M.: Mineral bone disorder in chronic kidney disease: head-to-head comparison of the 5/6 nephrectomy and adenine models. BMC Nephrol 2014, 15,69 .

8. Fries J.W., Sandstrom D.J., Meyer T.W., Rennke H.G.: Glomerular hypertrophy and epithelial cell injury modulate progressive glomerulosclerosis in the rat. Lab Invest $\mathrm{J}$ Tech Methods Pathol 1989, 60, 205-218.

9. Gagnon R.F., Duguid W.P.: A reproducible model for chronic renal failure in the mouse. Urol Res 1983, 11, 11-14.

10. Gibb I.A., Hamilton D.N.: An experimental model of chronic renal failure in mice. Clinical Immunol Immunopathol 1985, 35, 276-284.

11. Hauet T., Mothes D., Goujon J.M., Caritez J.C., Carretier M., Le Moyec L., Eugene M., Tillement J.P.: Trimetazidine prevents renal injury in the isolated perfused pig kidney exposed to prolonged cold ischemia. Transplantation 1997, 64, 1082-1086.

12. Lin F., Cordes K., Li L., Hood L., Couser W.G., Shankland S.J., Igarashi P.: Hematopoietic stem cells contribute to the regeneration of renal tubules after renal ischemia-reperfusion injury in mice. J Am Soc Nephrol 2003, 14, 1188-1199.

13. Makino H., Theng L.Z., Kumagai I., Takatori K., Ota Z., Yoshifusa H.: Progressive glomerular sclerosis and renal failure in rat with $7 / 8$ nephrectomy model. Nihon Jinzo Gakkai Shi 1990, 32, 127-136.

14. Naiman J.H., Mayhew P.D., Steffey M.A., Culp W.T., Runge J.J., Singh A.: Laparoscopic treatment of ovarian remnant syndrome in dogs and cats: 7 cases (2010-2013). J Am Vet Med Assoc 2014, 245, 1251-1257.

15. Ploussard G., Haddad R., Loutochin O., Bera R., Cabrera T., Malibari N., Scarlata E., Derbekyan V., Bladou F., Anidjar M.: A combination of hemostatic agents may safely replace deep medullary suture during laparoscopic partial nephrectomy in a pig model. J Urol 2015, 193, 318-324.

16. Sandin R., Feuk U., Wahlberg J., Modig J.: Effects of diltiazem on postischaemic renal cortical microcirculation in the pig. Acta Anaesthesiol Scand 1991, 35, 424-429.

17. Song L., Dianji F., Zhanyi W., Lulu Z., Zhaorong N., Yanwei G.: Establishment of a miniature pig model of mandibular osteoradionecrosis. West China J Stomatol 2015, 33, 570-574. 
18. Stein G., Busch M., Müller A., Wendt T., Franke C., Niwa T., Franke S.: Are advanced glycation end products cardiovascular risk factors in patients with CRF? Am J Kidney Dis 2003, 41, 52-56.

19. Wen C.T., Chu Y., Yeh C.J., Liu C.Y., Yuan H.C., Ko P.J., Liu Y.H., Liu H.P.: Feasibility and safety of endoscopic transumbilical thoracic surgical lung biopsy: a survival study in a canine model. J Surg Res 2013, 183, 47-55.

20. Yamaguchi I., Myojo K., Sanada H., Takami A., Suzuki Y., Imaizumi M., Takada C., Kimoto N., Saeki K., Yamate J., Takaba K.: Five-sixth nephrectomy in female common marmosets (Callithrix jacchus) as a chronic renal failure model a longitudinal course of serum biochemical, hematological and histopathological changes. J Toxicol Pathol 2014, 27, 183-195.

21. Zhang H., Liu T., Wang Y., Liu H.F., Zhang J.T., Wu Y.S., Lei L., Wang H.B.: Laparoscopic left hepatectomy in swine: a safe and feasible technique. J Vet Sci 2014, 15, 417-422.

22. Zhong D.H., Li Q.H., Di H., Shi L., Jian D.G.: Icariin protects rats against 5/6 nephrectomy-induced chronic kidney failure by increasing the number of renal stem cells. BMC Complement Altern Med 2015, 15, 378 . 